\title{
COMPLICAÇÕES NEUROLÓGICAS NO DECURSO DE TRATAMENTO PELO ACTH. A PROPÓSITO DE UM CASO DE AGNOSIA VISUAL
}

\author{
O. Freitas Juliño*
}

Licio M. Assis **

Julio Pereira Gomes ***

Acidentes neurológicos surgidos no decurso do tratamento pela cortisona e pelo ACTH têm sido relatados, alguns de menor importância em virtude de sua transitoriedade, outros realmente graves, por se subordinarem a lesões irreparáveis do sistema nervoso.

Ao lado das alterações psíquicas, bem estudadas por Delay e col. ${ }^{1}$, Frank $^{2}$, Lauras e outros, as manifestações convulsivas têm sido as complicações mais freqüentemente assinaladas no setor pròpriamente neurológico. Assim, Soffer e col. ${ }^{3}$ observaram, entre as complicações do tratamento de 34 casos de lupus erimatoso pelo ACTH e cortisona, a ocorrência de importantes alterações psíquicas e de crises convulsivas. As primeiras traduziram-se, em 6 pacientes, por síndrome depressiva, apatia, acompanhada num caso de incontinência esfinctérica, fenômenos alucinatórios e tentativas de suicídio. As crises convulsivas manifestaram-se em 4 casos, num dos quais desenvolveu-se status epilepticus, vindo o paciente a falecer 2 dias após a primeira convulsão e 11 dias após o início do tratamento pelo ACTH. Recordam, no entanto, os referidos autores a possibilidade da ocorrência de convulsões em pacientes com lupus eritematoso disseminado não tratado, conforme assinalaram Klumperer, Pollack e Baber; notam, porém, que o quadro convulsivo apresentou-se em tais casos como manifestação terminal da moléstia. Desordens convulsivas também na vigência de tratamento pelo ACTH foram observadas por Dorfmann e col. ${ }^{4}$ em 3

Trabalho realizado na Clínica Neurológica da Fac. Med. da Univ. de São Paulo (Prof. A. Tolosa) e na Clínica de Nutrição do Hospital das Clínicas (Dr. Helio L. Oliveira).

* Livre-Docente e assistente da Clínica Neurológica.

* Assistente da Clínica de Moléstias da Nutrição.

*** Médico interno do Hospital das Clínicas (Clínica Oftalmológica, Prof. Cyro de Rezende).

Nota dos autores - Agradecemos a colaboração que nos foi prestada pelos Drs. Antonio M. Leão Bruno, que gentilmente realizou os testes psiquiátricos em nosso paciente; Paulo $B$. Magalhães, que realizou alguns exames oftalmológicos $\mathrm{e}$ Adail F. Julião, que procedeu aos exames eletrencefalográficos. 
pacientes, que entraram em "estado de mal", quando ainda doses relativamente pequenas do medicamento tinham sido empregadas.

Também Lowell e col..$^{5}$ relataram o caso de um paciente que, por ocasião do tratamento de asma pela cortisona, na dose de $200 \mathrm{mg}$ diários, durante 15 dias, foi acometido quatro vêzes de crises convulsivas, sem que nos antecedentes jamais tivesse apresentado qualquer manifestação to típo epiléptico.

Estudos experimentais com contrôle eletrencefalográfico demonstraram, por outro lado, o efeito da cortisona e ACTH no sentido de baixar o limiar de convulsóes determinadas pelo eletrochoque e, mais recentemente, pelo pentametilenotetrazol, conforme estudos procedidos por Torda e Wolff ${ }^{3}$.

A observação que apresentamos a seguir constitui exemplo de uma série de graves distúrbios neurológicos conseqüentes a uma crise hịpertensiva, ocorrida no decurso do tratamento de um caso de sindrome nefrótjca pelo hormônio adrenocorticotrópico.

\section{OBSERVAÇÃO}

B. A. D. Jr., preto, com 8 anos de idade, admitido no Serviço de Moléstias da Nutrição do Hospital das Clínicas (reg. 212369) a 21-6-1950. Segundo informações da mãe do paciente, a doença teve início 5 meses antes, sem processo infeccioso prévio, com edema de rosto, especialmente das pálpebras, e que se generalizou em poucos dias para todo o corpo. O exame de urina realizado ne'ssa ocasião revelou albuminúria acentuada, cilindrúria e freqüentes hemácias. Submetido, durante 2 meses, a repouso no leito, restrição relativa de sal e líquiidos, não foi notada diminuição significativa do edema, persistindo acentuada oligúria. Como não melhorasse com essas medidas terapêuticas, e após se ter submetido a várias transfusões de sangue, foi internado. Nos antecedentes mórbidos assinala-se apenas a existência de bronquite crônica iniciada aos 7 anos de idade, com períodos de agravação no inverno e após resfriados. Ao exame clínico apresentava-se intensamente edemaciado, com ascite, hidrotórax direito, edema escrotal. O exame do aparêlho cardiovascular foi normal e, quanto ao aparêlho pulmonar, assinalou-se a existência de alguns estertôres em ambos os pulmões e presença de líquiido na base direita. Os exames de laboratório, realizados na primeira semana de internação, revelaram: soroproteínas $3,9 \mathrm{~g} / 100 \mathrm{ml}$; soroalbuminas $2,1 \mathrm{~g} /$ $100 \mathrm{ml}$; soroglobulinas $1,8 \mathrm{~g} / 100 \mathrm{ml}$ (método de Gornall-Bardawill-David com leitura espectrofotométrica); colesterol no sôro $343 \mathrm{mg} / 100 \mathrm{ml}$ (método de Scheftel com leitura espectrofotométrica); hemácias 4.600 .000 por $\mathrm{mm}^{3}$; hemoglobina 13,1 $\mathrm{g} / 100 \mathrm{ml}$; densidade da urina 1.023 ; albuminúria $16 \mathrm{~g} / \mathrm{l}$;" presença de lipóıdes birrefringentes na urina; presença de cilindros hialinos, granulosos e céreos e raras hemácias no sedimento urinário. Com o diagnóstico de síndrome nef rótica, foi submetido a regime dietético (dieta de arroz de Kempner e vitaminas) por todo o período de internação (21-12-50 a 28-2-52). Durante êsse período, recebeu três séries de tratamento pelo hormônio adenocorticotrópico por via intramuscular. A repetição destas séries de ACTH foi motivada, ou pela remissão incompleta da síndrome, ou pela recidiva que teve lugar após a interrupção da administração hormonal. Os períodos de administração, a duração de cada período, a dose diária e a dose total de ACTH recebida pelo paciente em cada período estão discriminados na tabela 1. 


\begin{tabular}{|c|c|c|c|c|}
\hline \multicolumn{2}{|r|}{ Períodos } & Duração & Dose diária & Dose total \\
\hline 1 & $12-1$ a $20-2-51 \ldots$ & 40 & 20 & 800 \\
\hline 2 & $9-5$ a $12-7-51 \ldots$ & 65 & 20 & 1.300 \\
\hline \multirow{2}{*}{3} & $16-8$ a $1-9-51$ & 17 & 20) & 340 \\
\hline & $2-9$ a $5-10-51 \ldots$ & 34 & 37,5 & 1.275 \\
\hline
\end{tabular}

Tabela 1

Nos dois primeiros períodos, o ACTH foi administrado na dose de $20 \mathrm{mg}$ por dia ( $10 \mathrm{mg}$ cada 12 horas). Porque a remissão foi incompleta com o primeiro período de tratamento, justificou-se um segundo período de ACTH. Poucas semanas após a interrupção do hormônio, a reinstalação da síndrome exigiu o terceiro período de administração hormonal; neste período a dose dićria de ACTH foi de $20 \mathrm{mg}$ por dia, mas no $18^{\circ}$ dia foi elevada para $37,5 \mathrm{mg}(12,5 \mathrm{mg}$ cada 8 horas). Com êste período de tratamento, que teve a duração de 51 dias, a síndrome nefrótica regrediu inteiramente, tendo persistido apenas albuminúria; as soroproteínas, colesterolemia se normalizaram e o edema desapareceu. A pressão arterial se manteve durante todo tempo de internação entre valores de 98-60 e 120-70 $\mathrm{mm} \mathrm{Hg}$, não tendo havido variações significativas durante os diversos períodos de administração hormonal.

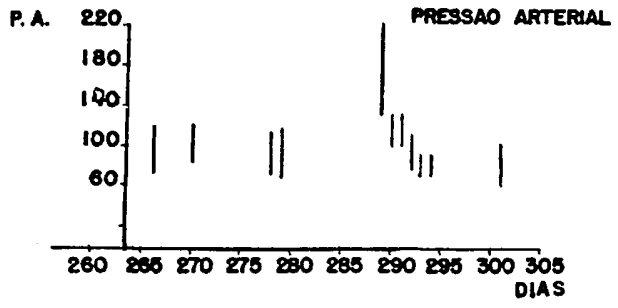

Esquema 1 - Variações da pressâo arterial entre os $265^{\circ}$ e $305^{\circ}$ dias de internação; crise hipertensiva no $289^{\circ}$ dia (6-10-1951).

No dia 6-10-1951 queixou-se, pela manhã, de intensa cefaléia, verificando-se que a pressão arterial nesse momento era de 220-130 $\mathrm{mm} \mathrm{Hg}$; por êsse motivo o ACTH foi interrompido a partir dêsse dia. Na mesma manhã, o exame dos fundos oculares revelou a existência de espasmo das arteríolas e edema da retina; as papilas eram normais. Ảs 12 horas e 30 minutos a pressão arterial já havia descido a 128-60 $\mathrm{mm} \mathrm{Hg}$ e a cefaléia tinha desaparecido. No dia seguinte manifestou-se, no período da manhã, violenta crise convulsiva, de tipo generalizado, tônico-clônica, após o que o paciente entrou em estado de coma. Nesse dia (7-10-1951), a pressão arterial era de $130-100 \mathrm{~mm} \mathrm{Hg}$; não havia rigidez de nuca, nem sinal de Babinski, verificando-se apenas hiporreflexia profunda generalizada. Uma punção suboccipital, realizada no dia 8 , revelou hipertensão liquórica: pressão inicial $29 \mathrm{~cm}$ de água (manômetro de Claude) e pressão final 14, após a retirada de $10 \mathrm{~cm}^{3}$ de líquor. $O$ paciente permaneceu em estado torporoso até o dia 11. No dia 12, apresentava-se em estado de grande agitação psicomotora, respondendo incoerentemente às perguntas que lhe eram feitas, em franco estado confusional. Novo exame de líquor revelou normalidade de pres- 
são e aspecto límpido e incolor. Melhoras progressivas estabeleceram-se nos dias seguintes, porém, no dia 15 , observou-se que o paciente estava totalmente amıaurótico. $O$ exame oftalmoscópico, feito no dia seguinte, revelou normalidade dos fundos oculares. Alguns dias depois (29 outubro), era o próprio paciente que informava "nada enxergar", não distinguindo nem mesmo a claridade.

A 2 novembro, novo exame oftalmoscópico mostrava, como o anterior, normalidade dos fundos oculares. No dia 5 , o paciente referia ter melhorado, pois já distinguia luminosidade e vultos, embora fôsse incapaz de reconhecer objetos ou pessoas. A 22 dêsse mesmo mês, o exame dos fundos oculares demonstrou, pela primeira vez, à esquerda, papila esbranquiçada no setor temporal e ediema da retina acompanhando os vasos. A 21-1-1952 verificava-se que o setor temporal da papila direita estava também mais claro e o da esquerda, nìtidamente esbranquiçado. As pupilas eram normais, com os reflexos conservados.

A 28-2-52, o paciente recebeu alta da enfermaria, pràticamente curado da nefrose, continuando, no entanto, a manifestar a impossibilidade de reconhecer ob. jetos e pessoas, apresentando ainda certa dificuldade para orientar-se. Assim, ao andar, chocava-se com os móveis e paredes e, às vêzes, parava, sem saber que direção tomar. Esta dificuldade foi gradativamente se atenuando, "aprendendo" então (no dizer da progenitora do paciente) a "orientar-se dentro de casa e a evitar obstáculos". A princípio "desconhecia" também as várias partes de seu próprio corpo, sendo incapaz de localizá-las quando interrogado.

A 29-10-1952, novo exame dos fundos oculares confirmou os dados anteriores, tendo-se acentuado a palidez da metade temporal da papila esquerda. A impossibilidade do reconhecimento pela visão, dos objetos e pessoas permanece até hoje com os mesmos característicos.

Exame físico (10-9-1953) - Estado geral bom. Pele e anexos normais. Não há edemas. Sistema muscular normotônico e normotrófico. Amígdalas hipertrofiadas e hiperemiadas. Nada de anormal quanto aos aparelhos respiratório, circulatório e digestivo. Pressão arterial 125-85 mm $\mathrm{Hg}$.

Sistema nervoso - Paciente destro. Equilíbrio normal. Motilidade voluntária conservada. Fôrça muscular segmentar normal. Coordenação muscular e tonicidade normais. Marcha normal (cautelosa em virtude dos distúrbios visuais). Mímica, palavra, mastigação e deglutição normais. Reflexos estilio-radial, cúbitopronador, bicipital e tricipital fracos de ambos os lados, assim como os patelares. Aquíleos normais. Axiais da face pouco evidentes. Cutaneoplantar em flexão. Cutâneo-abdominais normais. Palmo-mentoneiro ausente. Ausentes os sinais de Mendel-Bechterew e Rossolimo. Sensibilidades superficiais (táctil, dolorosa e térmica) conservadas, assim como as profundas (noção das atitudes segmentares, vibratória, visceral, dolorosa profunda, barognóstica e estereognóstica). Pares cranianos: excetuando-se as alterações relativas à visão (referidas a seguir), nenhuma outra anormalidade a assinalar. Olfação, gustação e audição normais.

Exame oftalmológico (10 setembro 1953) - $O$ observador colocando-se em face do paciente e pedindo-lhe que olhe para determinado objeto, verifica que êle não o encara de frente, mas dirige os olhos para a direita, dando a impressão de não estar fixando o objeto. Pedindo-lhe, contudo, que o aponte, êle o faz corretamente. Deslocando-se o objeto para um e outro lado, verifica-se que os olhos também se deslocam acompanhando-o, embora persista sempre a aparente falta de relação entre o deslocamento do objeto e a do globo ocular.

Motilidade extrínseca ocular conservada. Os movimentos isolados, como os associados, executam-se normalmente, com exceção do movimento de convergência, que não se realiza à direita. Reflexo do piscamento à ameaça presente bilateralmente. Pupilas isocóricas, reagindo nitidamente à luz. Reflexo consensual um pouco lento à esquerda. Reflexo da acomodação apenas esboçado. Acuidade visual: pesquisa prejudicada. Campo visual: impossível uma avaliação exata, por falta de cooperação do paciente. Úma pesquisa grosseira (por confronto) sugere 
a existência de distúrbios dos campos visuais nas metades direitas (provável hemianopsia homônima lateral direita $)^{*}$. Fundos oculares: à direita, papila de limites, coloração e níveis normais, sendo o lado temporal mais claro; à esquerda, nítida palidez do setor temporal da papila (atrofia temporal); aspecto normal da retina e dos vasos.

Gnosia visual - Reconhecimento de objetos e pessoas: o paciente é absolutamente incapaz de reconhecer, pela visão, os objetos que the são apresentados, ou de descrever suas características fundamentais. Erra em tôdas as provas, dando em geral respostas ao acaso. Identifica, porém, imediatamente o objeto quando o apreende em suas mãos, ou por intermédio de impressões auditivas ou olfativas. E' também incapaz de identificar as pessoas, conforme pudemos verificar em vários testes. A mãe do paciente informa também que êste, em casa, embora se oriente perfeitamente bem, evitando quaisquer obstáculos, é totalmente incapaz de identificar pela visão os objetos e pessoas, confundindo mesmo os pais e irmãos. Embora passe os dias brincando com os meninos, jogando bola, andando de velocípede, etc., não consegue encontrar os brinquedos se êstes fôrem retırados dos lugares onde os havia deixado. A identificação das côres é também impossível. Mesmo a evocação das côres encontra-se sacrificada. Reconhecimento dos símbolos gráficos, prejudicado.

Orientação espacial - $\mathrm{O}$ paciente descreve com exatidão itinerários simples e que lhe são habituais. Orienta-se corretamente no meio familiar e também nas proximidades de sua casa (costuma ir sòzinho ao empório e à farmácia, distantes dois quarteirões de sua moradia). Orientação direita-esquerda e memória topográfica conservadas.

Somatognosia - Conservada a noção do esquema corpóreo (distúrbios da somatognosia estiveram presentes apenas na fase inicial dos acidentes neurológicos: ver anamnese). Ausência de agnosia digital.

Praxia - Os movimentos intransitivos (elementares, expressivos, descritivos e gestos simbólicos) são normalmente executados. Dos movimentos transitivos, apenas $o$ ato de vestir-se é realizado com dificuldade e defeituosamente. $O$ paciente não consegue, por exemplo, vestir corretamente a camisa. Ao tentar fazê-lo, erra em tôdas as tentativas, percebendo, entretanto, haver errado. Somente consegue acertar quando a mãe coloca a camisa na posição em que está habituado a recebê-la para vestir-se. Consegue abotoar e desabotoá-la perfeitamente. Erra também, muitas vêzes, ao vestir a blusa e a calça, colocando-as às avessas, assim como atrapalha-se frequientemente ao pôr as meias. Calça os sapatos, porém muitas vêzes "troca os pés" e não consegue dar o laço nos cordões. O ato de despir-se é realizado, ao contrário, de modo pràticamente normal, em todos os seus tempos. Outros gestos espontâneos executam-se também normalmente.

Os atos transitivos intencionais (como acender uma vela, dar um nó, abrir uma porta com uma chave, etc.) são realizados com pequenas incorreções devidas aparentemente à visuo-agnosia, assim como os movimentos de imitação. Normais os atos transitivos de memória.

Praxia construtiva: desenhos geométricos simples são executados com alguma imperfeição em consequiência das desordens visuais.

Linguagem - Não há distúrbios da linguagem. A articulação da palavra e - vocabulário são normais, assim como a compreensão da palavra falada. Leitura e escrita prejudicadas (o paciente apenas havia iniciado o curso de alfabetização quando foi acometido pelos distúrbios neurológicos).

* Exames posteriores serão necessários para apurar-se precisamente os distúrbios dos campos visuais, visto que a falta de cooperação do paciente não permite afirmar com segurança a disposição das referidas alterações. 
Exame psíquico - Atenção normal. Percepções tácteis, auditivas, olfativas e gustativas bem apuradas. Nada digno de nota quanto à memória, excetuando-se a amnésia lacunar relativa ao período agudo dos acidentes neurológicos. Forma e conteúdo do pensamento sem alterações. Nível intelectual muito bom, verificado pelos testes de Binet-Simon, Goddard, Terman e Merrill. Afetividade adequada. Expressão e iniciativa inteiramente satisfatórias.
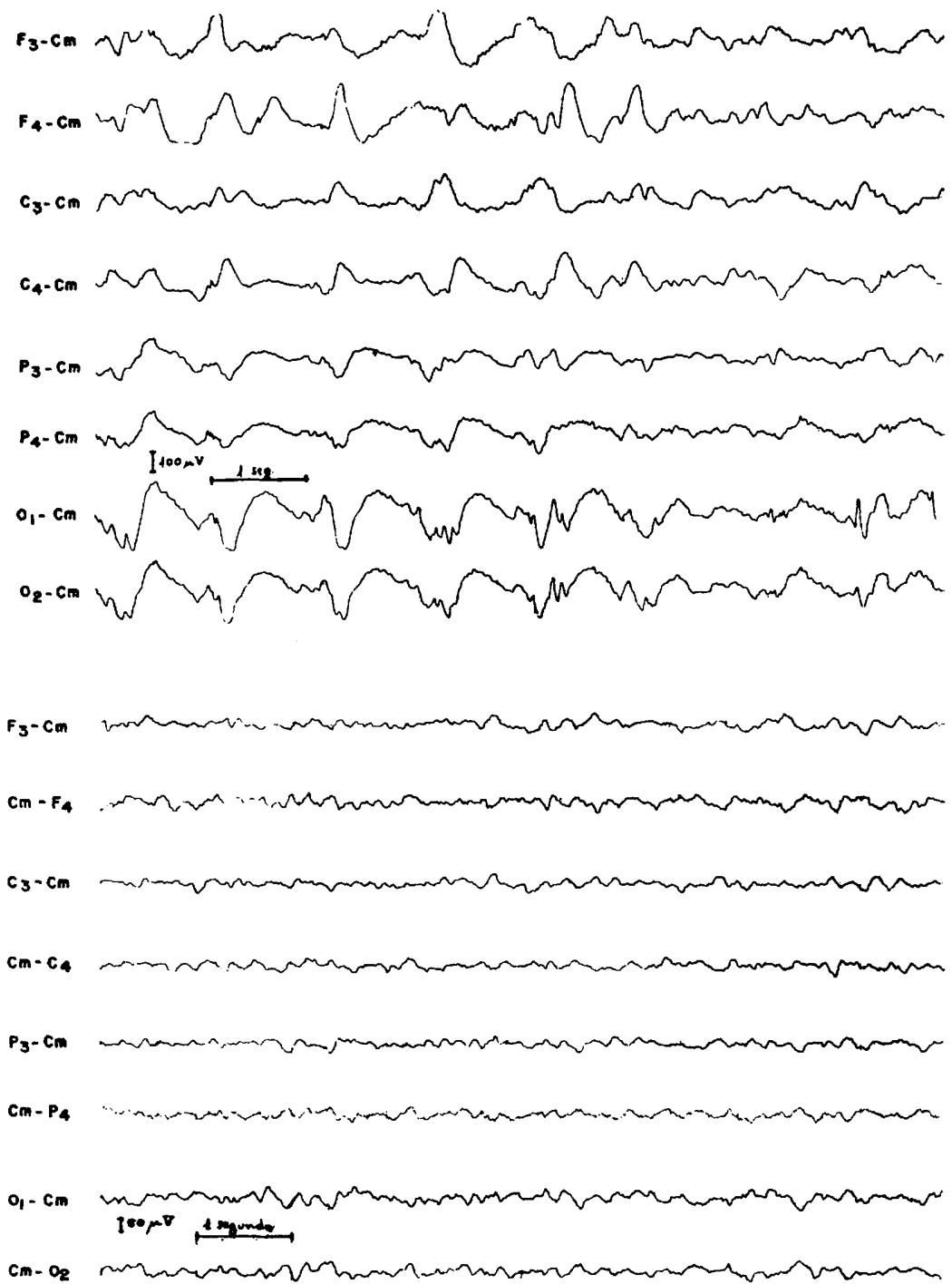

Fig. I - Na parte superior, traçado eletrencefalográfico obtido em 9 outubro $\left(n^{\circ} 645\right)$ : ondas $\delta(11 / 2$ a $3 \mathrm{c} / \mathrm{s})$, irregulares, difusas e ondas "sharp" nas áreas occipitais. $\mathrm{Na}$ parte inferior, EEG em 2-2-1952 ( $n^{\circ}$ 826) : anormalidade contínua, difusa (ondas 3 a 6 c/s.). 


$$
\text { (1) }
$$

Fig. 2 - EEG em 4-10-1952 (n 1207) : anormalidade contínua, difusa. Assimetria entre as regiões temporais: à esquerda, ondas 3 a $4 \mathrm{c} / \mathrm{s}$, de amplitude elevada, em pequenos surtos; ausência de ritmo $a$.

Exames complementares - Exames eletrencefalográficos (figs. 1 e 2): $1^{\circ}$ ) $\mathrm{N}^{\circ}$ 645, em 9-10-1951. Paciente em torpor. Ondas $\delta$, com frequiência de $1 \frac{1 / 2}{2} 3 \mathrm{c} / \mathrm{s}$, de grande amplitude, foram registradas em tôda a área cerebral explorada, ao lado de ondas rápidas, 15 a $20 \mathrm{c} / \mathrm{s}$, de pequena voltagem, superpostas ou intercaladas; nas regiões occipitais foram também evidenciadas numerosas ondas "sharp", 
mais numerosas e de maior amplitude à esquerda. $2^{\circ}$ ) No 826, em 2-2-1952. Exame em condições satisfatórias de cooperação. Foram registradas ondas 3-6 $\mathrm{c} / \mathrm{s}$, de média voltagem (40-70 microvolts), difusas, não havendo assimetria entre áreas homólogas. Nas regiões occipitais, assim como nas demais áreas, não foram assinaladas ondas de freqüências correspondentes às do ritmo $\alpha(8-13 \mathrm{c} / \mathrm{s})$. Durante a hiperpnéia foram evidenciados numerosos surtos de ondas de elevada voltagem (200-250 microvolts), com a frequiência de $3-31 / 2 \mathrm{c} / \mathrm{s}$, bilaterais, síncronas. $\left.3^{\circ}\right) \mathrm{N}^{\circ}$ 1207, em 4-10-1952. 'Traçado de repouso irregular, constituído quase exclusivamente por ondas 4-6 c/s, de voltagem média; o ritmo $\alpha$ é pràticamente inexistente. Entre as regiões temporais evidenciou-se uma assimetria no tracado de repouso e durante a hiperventilação: à esquerda, foram registradas ondas 3-4, $\mathrm{c} / \mathrm{s}$, de amplitude elevada (100-150 microvolts), em pequenos surtos. $\left.4^{\circ}\right) \mathrm{N}^{\circ}$ 1961, em 2-9-1953. Em comparação com o exame anterior, verificamos que persiste a desorganização difusa ocasionada pela presença de ondas 4-6 c/s, irregulares, e a inexistência de ritmo $\alpha$ definido. A assimetria entre as regiões temporais, referida no último exame, só se evidenciou durante a hiperventilação. $L i$ qüido cefalorraqueano (8-10-1950): Punção suboccipital, deitado. Pressão inicial $29 \mathrm{~cm}$ de água e pressão final 14, após a retirada de $10 \mathrm{ml}$ de líquor. Citologia, 0. Proteínas totais $10 \mathrm{mg} / 100 \mathrm{ml}$. Cloretos $690 \mathrm{mg} / 100 \mathrm{ml}$. Glicose $106 \mathrm{mg} / 100$ ml. Reações das globulinas, negativas; do benjoim e Takata-Ara, negativas. R. Wassermann, Steinfeld e Weinberg negativas. Exames oftalmológicos: Em 10-101951, fundos oculares: espasmos das arteríolas em $\mathrm{AO}$; edema da retina; papilas normais. Em 16-10-1951, fundos normais. Em 2-11-1951, fundos normais (o paciente não colabora nos exames subjetivos). Em 22-11-1951, acuidade visual: percepção luminosa apenas. Exame externo: pupilas normais, com reflexos presentes. Fundos: à direita, papila de limites, coloração e nível normais; à esquerda, papila de limites, coloração e nível normais, menos no setor temporal, que se apresenta esbranquiçado. Edema da retina acompanhando os vasos (Dr. Paulo B. Magalhães). Em 21-1-1952, fundos: à direita, papila de limites, coloração e nível normais (o lado temporal é mais claro); à esquerda, setor temporal bem esbranquiçado; pigmento na região macular junto à papila; vasos normais (Dr. Paulo B. Magalhães). Em 29-8-1952, fundos: à direita, papila de limites, coloração e níveis normais, sendo o lado temporal mais claro; à esquerda, nítido esbranquiçamento do setor temporal da papila, com limites nítidos; aspecto da retina e dos vasos, normal; em conclusão, atrofia temporal da papila do ôlho esquerdo.

\section{COMENTARIOS}

Num menino de 8 anos de idade, que se submetia ao tratamento pelo ACTH, desenvolveu-se uma crise hipertensiva acompanhada de edema cerebral, que se manifestou inicialmente por cefaléia intensa, depois por crise convulsiva generalizada, à qual se seguiu estado comatoso e, posteriormente, sindrome confusional. A encefalopatia hipertensiva condicionou, como alterações neurológicas mais importantes, perturbações visuais, ao lado de distúrbios somatognósticos, êstes de caráter transitório (autotopoagnosia).

Os distúrbios visuais apresentaram-se, a princípio, sob a forma de amaurose total (provável cegueira cortical, os fundos oculares sendo então normais), substituída, no fim de alguns dias, por distúrbios da percepção de tipo agnóstico, persistentes até hoje. Esta vísuo-agnosia diz respeito aos 
objetos, pessoas, figuras simbólicas e côres. As dispraxias mencionadas na observação subordinam-se, a nosso ver, aos distúrbios vísuo-gnósticos.

As alterações dos campos visuais, que parecem assumir disposição de hemianopsia lateral homônima direita, são dignas de reparo dada a freqüencia com que se associam à agnosia visual. Stauffenberg ${ }^{\top}$ já assinalara $^{2}$ que a agnosia óptica se acompanha freqüentemente de hemianopsia. tendo-a encontrado 20 vêzes em 34 casos. Da mesma forma, Nodet ${ }^{7}$, em 1899, assinalava que a cegueira psíquica é sempre acompanhada de hemianopsia (geralmente direita), de acromatopsia, perda da invocação das côres (acromatopsia amnéstica) e, às vêzes, de agnosia para as côres. Também Lhermitte e Ajuriaguerra ${ }^{8}$ assinalam que a agnosia visual se apresenta muitas vêzes acompanhada por uma redução do campo visual relacionada a alteração das vias ópticas primárias. Este acometimento das vias ópticas primárias retrataria, no entanto, apenas extensão da lesão cerebral, a origem lesional da agnosia devendo ser procurada não no sistema óptico primário, mas nas áreas peri e parastriadas (áreas 18 e 19 de Brodmann). Neste mesmo sentido, Nielsen ${ }^{9}$, em excelente revisão que procedeu, em 1937, sôbre os casos anátomo-clínicos de cegueira psíquica publicadas até então, selecionou 13 observações, que lhe permitiram chegar a um certo número de conclusões relativas à lesão mínima capaz de produzir a agnosia visual para objetos. Estabeleceu, entre outros pontos, que lesões unilaterais do lobo occipital podem determinar a cegueira psíquica, sendo a cortiça das $2^{a}$ e $3^{\text {a }}$ circunvoluções dêsse lobo a área essencial para o reconhecimento dos objetos. Os estímulos alcançariam esta área através de conexões ipsilaterais, representadas pelos fascículos transversos occipitais de Sachs e Vialet, e contralaterais, através do esplênio do corpo caloso. Desta forma, eventuais lesões do esplênio impediriam que estímulos provenientes da cortiça calcarina do lado oposto atingissem a cortiça occipital dominante.

Quanto aos dados eletrencefalográficos obtidos no caso em estudo, verificamos que, no primeiro exame, realizado a 9-10-1951 e parcialmente prejudicado pelas condições do paciente (torpor), foram assinaladas ondas $\delta(11 / 2$ a $3 \mathrm{c} / \mathrm{s})$ irregulares, difusas, e ondas "sharp" nas áreas occipitais, com pequeno predomínio à esquerda. No segundo exame, realizado a 22-1952, encontrou-se anormalidade contínua, difusa (ondas 3 a $6 \mathrm{c} / \mathrm{s}$ ). Nos terceiro e quarto exames (procedidos a 4-10-1952 e 2-9-1953, respectivamente), verificou-se a persistência de anormalidade contínua, difusa, além de assimetria entre as regiões temporais e ausência do ritmo $\alpha$. As alterações eletrencefalográficas apontadas diferem, pela sua maior gravidade e persistência, das que têm sido referidas no decurso da adrenocorticoterapia, habitualmente mais discretas e transitórias. Assim, Hoefer e Glaser ${ }^{10}$ assinalaram como alterações mais significativas, em 15 pacientes tratados pelo ACTH, a redução na amplitude, regularidade e continuidade da actividade básica $\alpha$ e, por outro lado, o aparecimento de surtos repentinos de 
atividade lenta, de 3 a 7 ciclos por segundo, freqüentemente aumentados, na incidência e amplitude, pela hiperventilação.

O caso que apresentamos é, em muitos aspectos, semelhante a um dos pacientes observados por Dorfmann e col. ${ }^{4}$. Tratava-se de um menino, de 13 anos de idade, portador de dermatomiosite, em tratamento pelo ACTH. Surgiram, 16 dias após o início do tratamento, desordens psíquicas (estado confusional, desorientação, síndrome delirante, etc.), ocorrendo posteriormente três crises convulsivas. A seguir, o menino entrou em estado de mal, permanecendo em coma profundo durante 3 dias, com sinais de hemiparesia esquerda. Dois dias depois, recuperou a consciência e melhoras gradativas foram observadas. Durante algum tempo apresentou, entretanto, agnosia, apraxia e alterações graves da personalidade. Um ano após, o paciente ainda apresentava crises freqüentes do tipo psicomotor, apraxia e distúrbios da linguagem, entre os quais alexia.

RESUMO

Os autores relatam a observação de um menino de 8 anos de idade, portador de síndrome nefrótica tratada pelo ACTH e que apresentou uma série de graves distúrbios neurológicos conseqüentes a uma crise hipertensiva (a pressão arterial elevou-se a $220-130 \mathrm{~mm} \mathrm{Hg}$ ), ocorrida por ocasião dêsse tratamento. Manifestando-se inicialmente por cefaléia intensa, depois por crise convulsiva generalizada, à qual se seguiu estado comatoso e posteriormente síndrome confusional, a encefalopatia hipertensiva condicionou, como seqüelas neurológicas mais importantes, distúrbios visuais. Estes, que se apresentaram, a princípio, sob a forma de amaurose total, assumiram depois o aspecto de distúrbios da percepção, tipo agnóstico, persistentes ainda hoje. A agnosia visual refere-se aos objetos, pessoas, figuras simbólicas e côres.

\section{SUMMARY}

The patient, an 8-year-old boy, was given ACTH therapy for symptoms ascribed to nephrosis. On the 5lst day (October 7, 1951) of the third period of the treatment (see table 1) he complained of intense headache and, the next day, convulsive seizure occurred. His blood pressure arose during this period to $220-130 \mathrm{~mm} \mathrm{Hg}$ and cerebrospinal fluid showed hypertension. During the next four days the child was in a coma and later became confused. In the weeks that followed, he improved but the hypertensive encephalopathy caused, as the most important neurologic damage, severe visual disorders. At first, he was totally blind; afterwards he showed disturbances of recognition, in the form of a complete visual agnosia, for objects, persons, symbols and colors. This condition has continued until today. 


\section{BIBLIOGRAFIA}

1. Delay, J., Pichot, P., Page, J. e Aubry, J. L. - Étude expérimentale des modifications psychologiques produites par les traitements à l'ACTH et la cortisone. Encéphale, 61:393-406, 1952. 2. Frank, J. A. - An acute psychosis developing during therapy with ACTH. Am. Pract. a. Digest of Treatment, 2:400-402 (maio) 1951. 3. Soffer, J., Levitt, M. F. e Baehr, G. - Use of cortisone and adrenocorticotropic hormone in acute lupus erythematosus. Arch. Int. Med., 86: 558, 1950. 4. Dorfmann, A., Apter, N. S., Smull, K., Bergenstal, D. M. e Richter, R. B. - Status epilepticus coincident with use of pituitary adrenocorticotrophic hormone; report of three cases. J.A.M.A., 146:25-27 (5 maio) 1951. 5 . Lowell, F., Franklin, W., Beale, H. e Schiller, I. - Occurrence of convulsion seizures during treatment of asthma with cortisone acetate. New England $J$. Med., 244:49 (janeiro) 1951. 6. Torda, C. e Wolff, H. B. - Effect of cortisone and ACTH on the threshold of convulsions induced by pentamethylenetetrazol. Federat. Proc, 10:137 (março) 1951. 7. Cit. por Lhermitte e Ajuriaguerra 8. 8. Lhermitte, J. e Ajuriaguerra, J. - Psychopathologie de la Vision. Masson Ed., Paris, 1942. 9. Nielsen, J. M. - Unilateral cerebral dominance as related to mind blindiness. Arch. Neurol. a. Psychiat., 38:108-135 (julho) 1937. 10. Hoefer, P. F. A. e Glaser, G. H. - Effects of pituitary adrenocorticotropic hormone (ACTH) therapy. J.A.M.A., 143:620-624 (17 junho) 1950.

Av. Paulista, 2584, apt $32-$ São Paulo. 